\title{
No dual antiplatelet therapy in atrial fibrillation
}

Submitted: 15 April 2016; Accepted: 15 April 15 2016; Published online: 19 April 2016

Managing atrial fibrillation is common in daily practice and an important part of this management is deciding over the embolism prevention strategy. Oral anticoagulants (warfarin, acenocumarol, apixaban, rivaroxaban or dabigatran) and antiplatelets (acetylsalicylic acid or clopidogrel) are the two groups of drugs used to prevent embolism events. To choose wisely $\mathrm{CHA}_{2} \mathrm{DS}_{2}-\mathrm{VASc}$ embolism risk scale aids in making this decision. But, is dual antiplatelet therapy, acetylsalicylic acid plus clopidogrel, a correct option in embolism prevention in atrial fibrillation?

A primary source search was done in

\section{References}

1. Chamorro A. Dual antiplatelet therapy is not optimal for stroke prevention in patients with atrial fibrillation. Int. J. Stroke. 5, 28-29 (2010).

2. Connolly S, Pogue J, Hart R, et al. (2006)

Clopidogrel plus aspirin versus oral anticoagulation for atrial fibrillation in the Atrial fibrillation Clopidogrel Trial with Irbesartan for prevention of Vascular Events (ACTIVE W): a randomised controlled trial. Lancet. 367, 19031912.

3. Connolly SJ, Pogue J, Hart RG, et al. Effect of clopidogrel added to aspirin in patients with atrial fibrillation. N. Engl. J. Med. 360, 2066-2078 (2009).

4. Healey JS, Hart RG, Pogue J, et al. Risks and benefits of oral anticoagulation compared with
Pubmed (Medline) using as key words "dual antiplatelet therapy and atrial fibrillation" and the most relevant articles were chosen [1-4]. Secondary sources guidelines were also reviewed, but only two major guidelines discussed this matter, European Society of Cardiology [5] and Upto date [6]. The conclusion was that double anticoagulation was not an appropriate treatment for embolism prevention in atrial fibrillation. The risk of bleeding of dual antiplatelet therapy was similar to the anticoagulation therapy but the embolism prevention was much lower.

clopidogrel plus aspirin in patients with atrial fibrillation according to stroke risk: the atrial fibrillation clopidogrel trial with irbesartan for prevention of vascular events (ACTIVE-W). Stroke. 39: 1482-1486 (2008).

5. Camm AJ, Lip GY, De Caterina R, et al. 2012 ESC Committee for Practice Guidelines-CPG; Document Reviewers. 2012 focused update of the ESC Guidelines for the management of atrial fibrillation: an update of the 2010 ESC Guidelines for the management of atrial fibrillation-developed with the special contribution of the European Heart Rhythm Association. Europace. 14, 1385-1413 (2012).

6. Warren JM, Daniel ES, Gregory YHL. Atrial fibrillation:Anticoagulant therapy to prevent embolization. Europace. 14, 1385-1413 (2012).
Antonio L Aguilar-Shea** Centro de Salud Puerta de Madrid, Spain *Author for correspondence:

Tel.: +34918806699

antonio.aguilar@salud.madrid.org 